\title{
Permeability of Ocular Vessels and Transport Across the Blood-Retinal-Barrier
}

\author{
PER TÖRNQUIST, ALBERT ALM and ANDERS BILL \\ Uppsala and Umeå, Sweden
}

\begin{abstract}
Summary
This paper reviews quantitative studies on the permeability of retinal and choroidal vessels and the exchange of nutrients over the blood retinal barrier (BRB). The fenestrated capillaries in the choroid are very permeable to low molecular weight substances; sodium permeability in the choroid is probably 50 times that in skeletal muscle. This results in high concentrations and rapid turnover of nutrients in the extra-vascular compartment of the choroid. Free diffusion is restricted by the pigment epithelium barrier. Also the retinal capillaries, with tight junctions between the endothelial cells, have very low permeability even to sodium. The uptake index technique has provided evidence for several carrier systems in the BRB; hexoses, neutral and basic amino acids, and monocarboxylic acids, very similar to those found in the brain. At least for glucose and lactate these carriers operate at both levels of the BRB; the RPE and the endothelium of the retinal capillaries, and in both directions; i.e. inwards and outwards.
\end{abstract}

The blood-retinal (BRB) and the blood-brain (BRB) barriers are physical hindrances for diffusion between blood and nervous tissue. They are essential for the control of the microenvironment of the tissues:

* by preventing noxious water-soluble molecules from entering the extravascular spaces of the retina and the brain.

* by preventing uncontrolled escape of important ions from nervous tissue.

Due to these barriers there is a need for specific carrier-mediated mechanisms for the exchange, of nutrients and metabolites through the cells.

Since the retina in man and several other species has a dual vascular supply, the retinal and the choroidal vessels, the BRB has two parts, the endothelial cells of the retinal capillary walls and the retinal pigment, epithelium
(RPE). The barrier function depends on tight junctions which restrict intercellular movement of all water-soluble molecules and thus virtually prevent these molecules from entering retinal tissue between the cells. ${ }^{1}$ In clinical studies the integrity of the BRB can be evaluated by fluorescein angiography and vitreous fluorophotometry. These methods which provide qualitative, morphological and quantitative information on the permeability of the BRB have increased our understanding of the pathogenesis of many retinal diseases.

The aim of the present paper is to summarise some quantitative experimental studies, performed in our laboratory, on the permeability of the retinal and choroidal vessels and on the exchange of nutrients over the BRB.

\section{Permeability}

In our studies on capillary permeability the

From: Department of Ophthalmology and Department of Physiology and Medical Biophysics, University of Uppsala and Department of Ophthalmology, University of Umeå.

Correspondence to: Per Törnquist, MD, Department of Ophthalmology, University Hospital, S-751 85 Uppsala, Sweden. 
movement of an intra-arterially injected tracer through the capillary wall was determined. The permeability coefficient $(P)$ can be calculated according to the formula:

$$
\mathrm{P}=-(\mathrm{Q} / \mathrm{S}) \ln (1-\mathrm{E})(1)
$$

where $S$ is the capillary surface area, $Q$ the flow of tracer containing fluid and $E$ the extraction of the tracer. The derivation of the formula assumes that $\mathrm{E}$ represents a unidirectionally outflux of tracer, i.e. there is no back-diffusion from tissue to blood. Depending on the speed by which the tracer moves across the vessel wall different experimental designs must be used.

\section{Choroidal vessels \\ Macromolecules}

The permeability of the choroid to plasma proteins has been investigated in rabbits. ${ }^{2}$ Steady plasma levels of labelled proteins were obtained by intravenous injections. The animals were killed at different times and the radioactivity in various structures of the eye was measured. For about six hours the amount of labelled protein in the choroid gradually increased. The results indicated an apparent extravascular volume for albumin of $165 \mu \mathrm{l} / \mathrm{g}$, (plasma equivalents) and a turnover rate constant of $3.5 \% / \mathrm{min}$. From these results an albumin extraction of $0.019 \%$ was calculated. ${ }^{3}$ A permeability coefficient for albumin of $33 \times 10^{-8} \mathrm{~cm} / \mathrm{s}$ was calculated assuming a plasma flow of $630 \mu \mathrm{l} / \mathrm{min}$ through the choroidal vessels of the rabbit and an estimated capillary surface area of $6 \mathrm{~cm} .^{2}$ This figure is considerably higher than corresponding figures for fenestrated capillaries in the kidney cortex $\left(5.7 \times 10^{-8} \mathrm{~cm} / \mathrm{s}\right)$ and for non-fenestrated capillaries in skeletal muscle $\left(1.1 \times 10^{-8} \mathrm{~cm} / \mathrm{s}\right)$. The permeability of the choriocapillaries to $\mathrm{IgG}$ was about $50 \%$ of that to albumin. As pointed out by Bill et al. ${ }^{3}$ this high permeability to macromolecules may play a role in presenting retinol binding protein-prealbumin complex to the RPE.

\section{Small Molecules, the Single Injection Technique}

For more diffusible, low molecular weight substances with an expected rapid transcapillary movement, a technique with a high time resolution is required. For this reason we adopted the single injection technique ${ }^{4}$ and modified it for studies on the eye. ${ }^{5,6}$ After an intra-arterial bolus injection, blood samples are collected from the vein draining the investigated organ (Fig. 1). The bolus contains one or more test substances and one reference substance, selected because of its inability to escape from the intra-vascular volume during the passage through the tissue. Albumin is often used as a reference tracer in organs with non-fenestrated capillaries and it was found to fulfil the criteria of an intravascular tracer also in the fenestrated capillaries of the choroid.

The fractional extraction, E, of the test substance defined as the difference in concentration between the reference and the test substance divided by the concentration of reference substance was used to calculate the permeability coefficient.

The fractional extractions in the choroid of ${ }^{22} \mathrm{Na}$ and ${ }^{51} \mathrm{Cr}$-EDTA showed constantly declining values with time. A likely explanation is back-diffusion of test tracer from tissue to blood. The initial extractions $(0.66$ and 0.35

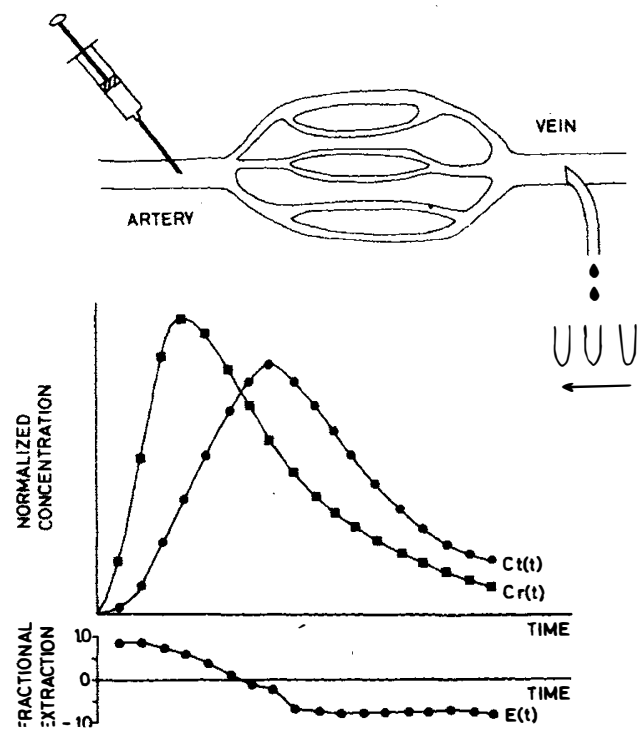

Fig. 1. Schematic illustration of the single injection technique. The concentrations of the intravascular reference substance, $\mathrm{Cr}$, and the test substance, $\mathrm{Ct}$, are determined in repeated venous samples after an intraarterial injection. The concentrations are normalised with regard to the concentrations in the injected solution and plotted against time. The extraction of the test substance at any instant, $E(t)$, is then calculated. $(E(t)=$ $1-C t(t) / C r(t))$. 
respectively), when back-diffusion is minimal, were therefore used for calculations of $P$, giving values of about 180 and $70 \times 10^{-5} \mathrm{~cm} /$ sec for ${ }^{22} \mathrm{Na}$ and ${ }^{51} \mathrm{Cr}$-EDTA respectively. Even though these values are 50 to 80 times higher than corresponding values in skeletal muscle ${ }^{7}$ there are reasons to believe that they are also influenced by back-diffusion and thus underestimate true values for P. However, similar permeability coefficients were found for the fenestrated capillaries of the salivary glands. ${ }^{8}$

To study the wash-out of test tracers from the tissue without interference of recirculation the injected bolus was delayed by use of an external shunting of blood from the abdominal aorta to the carotid artery. Within 20-25 sec, the extravascular compartment was completely cleared of ${ }^{51} \mathrm{Cr}$-EDTA and only a small fraction, about $3 \%$, of ${ }^{22} \mathrm{Na}$ remained in the extravascular space. This very high permeability of the choriocapillaries, and the rapid turnover in the extravascular space $\left(\mathrm{T}_{1 / 2}\right.$ for ${ }^{22} \mathrm{Na}$ and ${ }^{51} \mathrm{Cr}$-EDTA of two and four sec respectively) indicate that molecules such as glucose and amino acids are present at the RPE in concentrations not far from those in plasma. The concentration of glucose in the extravascular space of the choroid has been estimated to be $90-95 \%$ of that in blood. ${ }^{3}$

\section{Retinal Vessels}

For single injection studies on the retinal vessels access to retinal venous blood is crucial. In the pig there is a venous plexus around the optic nerve, close behind the globe, which drains retinal blood. ${ }^{9}$ Thus pigs were used to determine the permeability of the retinal vessels. The venous outflow curves of ${ }^{125} \mathrm{I}$-albumin and ${ }^{22} \mathrm{Na}$ after a bolus injection into the carotid artery were coincident, that is no extraction of ${ }^{22} \mathrm{Na}$ from retinal vessels could be demonstrated. This is consistent with results obtained in the brain. ${ }^{10}$ Thus the permeability of the retinal vessels to ions and low molecular weight substances is too low to be studied with the single injection technique.

Further evidence for the low permeability of the BRB to small substances has been provided by Lightman et al. ${ }^{11}$ They determined permeability surface area products (PS) for sucrose $\left(0.44 \times 10^{-5} \mathrm{ml} / \mathrm{g} / \mathrm{s}\right)$ and mannitol $\left(1.25 \times 10^{-5} \mathrm{ml} / \mathrm{g} / \mathrm{s}\right)$, values which are similar to those found in the brain. They also determined the tissue content of tracers following an intravascular injection and found similar values in the brain and the retina. Although their technique does not separate the relative contribution of the retinal capillaries and the RPE these results indicate that the permeability of both parts of the $\mathrm{BRB}$ is of the same order as that of the BBB.

\section{Transport}

\section{The Uptake Index Method}

We have modified the uptake index (UI) method, previously used in the brain by Oldendorf, ${ }^{12}$ for the retina of the rat. For comparisons between $\mathrm{BRB}$ and $\mathrm{BBB}$ samples from the brain were included. ${ }^{13,14} \mathrm{~A}$ mixture of a ${ }^{14} \mathrm{C}$ labelled test tracer and a highly diffusible reference tracer $\left({ }^{3} \mathrm{H}_{2} \mathrm{O}\right)$ was injected into a carotid artery (Fig. 2). Then tissue samples from the ipsilateral retina and brain were quickly prepared for analysis of radioactivity and the UI was calculated:

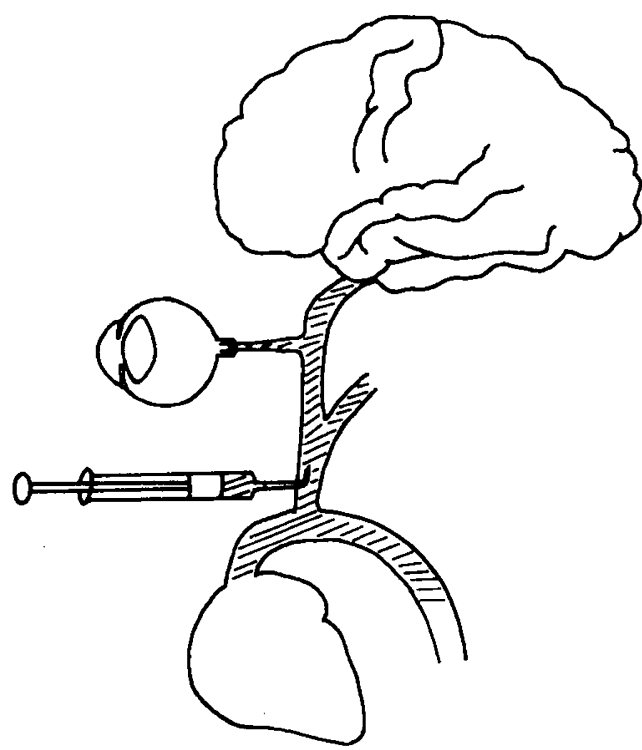

Fig. 2. Schematic illustration of the uptake index technique. The tissue concentration of the highly diffusible reference substance and the test substance are determined in retinal and brain samples, rapidly obtained after an intra-arterial injection. The UI, which expresses the tissue uptake of the test substance as a percentage of the uptake of the reference substance, is then calculated. 


$$
\mathrm{UI}(\%)=\frac{{ }^{14} \mathrm{C} /{ }^{3} \mathrm{H}-\text { tissue }}{{ }^{14} \mathrm{C} /{ }^{3} \mathrm{H}-\text { inj solut. }} \times 100(2)
$$

RUI and BUI express the fractional uptake of the ${ }^{14} \mathrm{C}$-labelled test substance as a percentage of the fractional uptake of the reference substance ${ }^{3} \mathrm{HOH}$ in retina and brain respectively.

A carrier-mediated transport shows saturability and, as a rule, stereo-specificity. The demonstration of one or both of these characteristics strongly indicates a carrier. If an unlabelled second test substance is added to the injected solution these molecules will compete with the labelled molecules at the carrier for a saturable transport i.e. the UI will be reduced.

If this second test substance is the same as the labelled substance saturability can be demonstrated (self-inhibition). Other unlabelled substances with affinity to the same carrier may also reduce UI (cross-inhibition).

It should be pointed out that the UI technique does not separate between transport at the two parts of the BRB. Thus the possibility of different carriers for the retinal capillary wall and the RPE can not be excluded. A contribution to the retinal uptake from the anterior part of the eye (ciliary epithelium through the vitreous) is probably negligible since the eye is enucleated within five sec following the injection and immediately frozen and the retina is prepared in a frozen condition. The UI technique will only demonstrate carriers able to facilitate passage of substances in the blood-to-tissue direction, and it will not necessarily differentiate between facilitated diffusion and active transport.

The UI technique has provided evidence for several carrier systems in the BRB, and the results demonstrate the similarities between the $\mathrm{BRB}$ and the $\mathrm{BBB}$ in this respect. Thus in both barriers there are separate carriers for transport of hexoses, including D-glucose,${ }^{15}$ neutral and basic amino acids, ${ }^{14}$ and monocarboxylic acids. ${ }^{16}$ Some minor differences between the two barriers have been observed, but they may well be due to the limited resolution of the technique.

Stereo-specificity and/or saturability of the passage of glucose through the BRB have been observed in several species. ${ }^{7,17,18}$ With the UI technique the presence of a carriermediated transport of glucose through the $\mathrm{BRB}$ as well as the BBB could be demonstrated. ${ }^{15}$ Apart from D-glucose, the carriers accept 2-deoxy-D-glucose, 3-O-methyl-Dglucose, D-mannose and D-galactose, but not L-glucose, D-fructose or D-ribose. The order of affinities seems to be the same in the BRB and the BBB, and phloretin and phloridizin reduce both retinal and brain uptake of $\mathrm{D}$-glucose. The results indicate a larger transport capacity for the BRB. ${ }^{15}$

There is a common carrier for the monocarboxylic acids L-lactate and pyruvate and for the ketone body 3-hydroxybutyrate in the $\mathrm{BRB}$ and the $\mathrm{BBB}$. The transport is $\mathrm{pH}$ dependent with an increased uptake at lower $\mathrm{pH}(6 \cdot 3)$. suggesting a cotransport of $\mathrm{H}^{+}$ions or counter-transport of $\mathrm{OH}^{-}$ions. ${ }^{16}$

In the BBB three separate, class-specific carrier systems, one each for large neutral amino acids, basic and acid amino acids have been characterised. ${ }^{19}$ It has been suggested that amino acids are delivered to the retina mainly from the ciliary epithelium through the vitreous body ${ }^{20}$ and that the RPE should have an absorbent transport function of amino acids out of the retina ${ }^{21}$ similar to that of the choroid plexus in the brain. ${ }^{22}$ With the UI-technique, however, we found in both the $\mathrm{BRB}$ and the BBB two separate, stereospeci-

Table Amino acids with an affinity to the neutral or the basic amino acid carrier in the $B R B$ and the $B B B$.

\begin{tabular}{ll}
\hline \multicolumn{1}{c}{ Neutral } & Basic \\
\hline L-Phenylalanine & L-Arginine \\
L-Tryptophan & L-Ornithine \\
L-Tyrosine & L-Lysine \\
L-Leucine & \\
L-Isoleucine & \\
L-Methionine & \\
L-DOPA & \\
L-Histidine & \\
L-Cycloleucine & \\
L-Valine & \\
\hline
\end{tabular}

L-phenylalanine and L-arginine were chosen as representatives for the neutral and the basic carriers respectively. If the UI of one of these compounds was reduced by the adding of an unlabeled amino acid to the injected solution, this second amino acid thereby demonstrates affinity to the carrier. 
fic, saturable carrier systems; one for large neutral amino acids and one for basic amino acids (Table).$^{14}$ In the brain, acid amino acids are transported by a separate lowcapacity carrier. ${ }^{19}$ We were unable to demonstrate such a carrier in either the BRB or the $\mathrm{BBB}$, but the sensitivity of the modified technique may be insufficient for studies on lowcapacity transport systems. A specific carrier for taurine was found in the BRB, but not in the $\mathrm{BBB} .{ }^{14}$ In all other respects the similarities between the results obtained for the BRB and those obtained for the BBB were striking, and a reasonable conclusion is that in the $\mathrm{BRB}$, as in the BBB, amino acids are transported by carrier-mediated facilitated diffusion. Thus these results do not support the concept of an absorptive, active transport system for amino acids in the tissue-to-blood direction as proposed by Reddy et al. ${ }^{23}$ The co-existence of carriers for facilitated, bidirectional diffusion and carriers for active, mainly indirectional transport of amino acids through the BRB is definitely unexpected and a question where further research is needed.

\section{Arteriovenous Differences:}

Tracer studies like the single injection technique and the UI technique ideally assumes a unidirectional flux over the barrier. Obviously it is of great interest also to measure the net flux of the molecules under investigation. If choroidal and retinal venous blood can be collected the relative contribution to the retinal nutrition, of transport across these two parts of the barrier, can be estimated. The possibility of sampling choroidal venous blood in cats ${ }^{24}$ and retinal venous blood in pigs $^{25}$ has been utilised for this purpose.

In the pig the a-v-differences for glucose was $0.07 \mathrm{mmol} / \mathrm{l}$ and $0.44 \mathrm{mmol} / \mathrm{l}$ for the choroid and retina respectively at an arterial concentration of $3.69 \mathrm{mmol} / \mathrm{l}^{25}$ Thus a glucose-carrier operates at the two sites of the BRB. The net extraction of glucose from the choroidal and retinal blood (2\% and $12 \%)$ corresponds to $121 \mathrm{nmol} / \mathrm{min}$ and $28 \mathrm{nmol} /$ min calculated for blood flow values of 1732 $\mathrm{mg} / \mathrm{min}$ and $64 \mathrm{mg} / \mathrm{min}$ for the two tissues. Since the choroid can be expected to utilise only a minor fraction (less than $4 \%$ ) of the glucose consumed by the two tissues together, about $80 \%$ of the glucose consumed by the retina was delivered from the choroid..$^{25}$ The extracted fraction of glucose is much larger ${ }^{15}$ than the net extraction which indicates that the carrier operates in both directions.

An unusually high rate of anaerobic glycolys has been shown in vitro. ${ }^{26}$ It was estimated that glucose and oxygen consumption in the retina of the pig was $110 \mu \mathrm{mol} / \mathrm{min} / 100 \mathrm{~g}$ and $224 \mu \mathrm{mol} / \mathrm{min} / 100 \mathrm{~g}$ respectively. Thus $63 \%$ of the glucose was not oxidised which indicates a high rate of lactate production also in vivo. Negative a-v-differences for lactate in retinal and choroidal blood show a net outflow to the blood under normoglycemia ${ }^{25}$ as has been demonstrated for the brain. ${ }^{27}$

\section{The Effect of Diabetes on the BRB}

It is well known that breakdown of the BRB is part of clinical diabetic retinopathy. It has even been suggested that an increase in BRB permeability to sodium fluorescein preceeds any other sign of diabetic retinopathy. ${ }^{28}$ Other investigators, however, have been unable to confirm this observation. ${ }^{29,30}$

Attempts to study the barrier function with vitreous fluorophotometry in an animal model-short-term, untreated-streptozotocin-induced diabetes in rats - have also given conflicting results. ${ }^{31-33}$ Some of the problems involved in these fluorophotometry studies can be avoided by using radioactively labelled tracers instead of fluoroscein for quantitation of BRB permeability. In one such study we were unable to demonstrate any increased permeability of either the BRB or the BBB after 1-2 weeks untreated diabetes in rats. ${ }^{34}$ The results, however, suggested that untreated diabetes may cause an intraretinal accumulation of weak acids, such as paraamino-hippuric acid. An outward-directed transport of weak acids and anions through the BRB has been described, ${ }^{35}$ and the possibility that fluorescein is transported out of the eye by this carrier may explain the variable results obtained with fluorescein in diabetic rats.

Diabetes may have other effects on the BRB than increased permeability. The possibility of an effect on the transport of glucose across the BRB as well as the BBB has been discussed. Insulin causes long-term regulation 
of the number of glucose carriers in the cell, and short-term activation/translocation of those in adipocytes and skeletal muscle. ${ }^{36,37}$ Thus insulin-dependent glucose transport seems to be influenced/regulated by insulin levels in plasma. Glucose transport through the $\mathrm{BRB}$ and $\mathrm{BBB}$, however, is not regulated by insulin, but previous studies have indicated that the glucose carrier in the BRB and the BBB may become adapted to chronic hyperglycemia through reduced $\mathrm{V}_{\text {max }}$ (maximum rate of transport) for the $\mathrm{BBB}^{38,39}$ or increased $\ddot{\mathrm{K}}_{\mathrm{m}}$ (concentration at which transport rate is half of maximum) for the BRB. ${ }^{40}$ DiMattio et $a l .{ }^{41}$ however, could not verify that short-term diabetic hyperglycemia has an effect on the transport kinetics of the glucose carrier in the $\mathrm{BRB}$, and in a recent study we observed that hyperglycemia induced by a three min glucose infusion has the same effect on glucose transport through the BRB and the BBB as two to three weeks untreated diabetes. ${ }^{42}$ The results could well be explained by competitive inhibition, although a rapid change-within minutes-of the kinetic characteristics of the glucose carriers cannot be excluded with such techniques. Still, our studies on diabetic rats have not provided any evidence that increased barrier permeability or disturbed glucose transport is an early sign in experimental diabetes.

\section{References}

${ }^{1}$ Cunha-Vaz JG: Sites and function of the blood-retinal barriers. In: Cunha-Vaz JG, ed. The bloodretinal barriers. New York and London: Plenum Press, 1980, 101-17.

${ }^{2}$ Bill A: Capillary permeability to and extravascular dynamics of myoglobin, albumin and gammaglobulin in the uvea. Acta Physiol Scand 1968, 73: 204-19.

${ }^{3}$ Bill A, Törnquist P, Alm A: Permeability of the intraocular blood vessels. Trans Ophthalmol Soc UK 1980, 100: 332-6.

${ }^{4}$ Crone C: Capillary permeability-techniques and problems. In: Crone C and Lassen NA, eds. Capillary Permeability. Copenhagen, Munksgaard, 1970, 15-31.

${ }^{5}$ Törnquist P: Capillary permeability in cat choroid, studied with the single injection technique. I. Bibl Anat 1976, 16: 51-5.

${ }^{6}$ Törnquist P: The indicator extraction technique, A method for studying the blood-retinal barriers. In: Eisenberg HM and Suddith RL, eds. Cerebral Microvasculature. Plenum Publishing Corporation 1980, 105-12.

${ }^{7}$ Törnquist $\mathrm{P}$ : Capillary permeability in cat choroid, studied with the single injection technique II. Acta Physiol Scan 1979a, 106: 425-30.
${ }^{8}$ Mann GE, Smaje LH, Yudilevich DL: Permeability of the fenestrated capillaries in the cat submandibular gland to lipid-insoluble molecules. J Physiol (London) 1979, 297: 335-54.

${ }^{9}$ Törnquist P, Alm A, Bill A: Studies on ocular blood flow and retinal capillary permeability to sodium in pigs. Acta Physiol Scand 1979, 106: 343-50.

${ }^{10}$ Yudilevich D and De Rose N: Blood-brain transfer of glucose an other molecules measured by rapid indicator dilution. Am J Physiol 1971, 220: 841-6.

${ }^{11}$ Lightman SL, Palestine AG, Rapoport SI, Rechthand E: Quantitative assessment of the permeability of the rat blood-retinal barrier to small water-soluble non-electrolytes. $J$ Physiol (London) 1987, 389: 483-90.

${ }^{12}$ Oldendorf WH: Brain uptake of radiolabelled amino acids, amines, and hexoses after arterial injection. Am J Physiol 1970, 221: 1629-39.

${ }^{13}$ A.lm A and Törnquist P: The uptake index method applied to studies on the blood-retinal barrier. I. A methodological study. Acta Physiol Scand 1981, 113: 73-9.

${ }^{14}$ Törnquist $P$ and Alm A: Carrier-mediated transport of amino acids through the blood-retinal and the blood-brain barriers. Graefe's Arch Clin Exp Ophthalmol 1986, 224: 21-5.

${ }^{15}$ Alm A, Törnquist P, Mäepea O: The uptake index method applied to studies on the blood-retinal barrier. II. Transport of several hexoses by a common carrier. Acta Physiol Scand 1981, 113: 81-4.

${ }^{16} \mathrm{Alm} \mathrm{A}$ and Törnquist P: Lactate transport through the blood-retinal and the blood-brain barrier in rats. Ophthalmol Res 1985, 17: 181-4.

${ }^{17}$ Dollery CT, Henkind P, Orme M: Assimilation of D and L I-C-14 glucose into the retina, brain, and other tissues. Diabetes 1971, 20: 519-21.

${ }^{18}$ Zadunaisky JA and Degnan KJ: Passage of sugars and urea across the isolated retinal pigment epithelium of the frog. Exp Eye Res 1976, 23: 191-6.

${ }^{19}$ Oldendorf WH and Szabo J: Amino acid assignment to one of three blood-brain barrier amino acid carriers. Am J Physiol 1976, 230: 94-8.

${ }^{20}$ Reddy VN: Dynamics of transport systems in the eye. Friedenwald Lecture. Invest Ophthalmol Vis Sci 1979, 18: 1000-18.

${ }^{21}$ Miller S and Steinberg RH: Transport of taurine, L-methionine and 3-O-methyl-D-glucose across. the frog retinal pigment epithelium. Exp Eye Res 1976, 23: 177-89.

${ }^{22}$ Bradbury M: The concept of blood brain barrier, New York. John Wiley and Sons, 1979, 178-82.

${ }^{23}$ Reddy VN, Chakrapani B, Lim CP: Blood-vitreous barrier to amino acids. Exp Eye Res 1977, 25: 543-54.

${ }^{24} \mathrm{Alm} \mathrm{A}$ and Bill A: Blood flow and oxygen extraction in the cat uvea at normal and high intraocular pressures. Acta Physiol Scand 1970, 80: 19-28.

${ }^{25}$ Törnquist $\mathrm{P}$ and Alm A: Retinal and choroidal contribution to retinal metabolism in vivo. A study in pigs. Acta Physiol Scand 1979, 106: 351-7.

${ }^{26}$ Warburg O: Über die Klassifizierung tierischer 
Gewebe nach ihrem Stoffwechsel. Biochem $Z$ 1927, 184: 484-8.

${ }^{27}$ Daniel PM, Love ER, Moorouse SR, Pratt OE, Wilson P: The movement of ketone bodies, glucose, pyruvate and lactate between the blood and the brain in rats. J Physiol (London) 1972, 221: 22-3.

${ }^{28}$ Cunha-Vaz JG, Fonseca JR, Abreu JF, Ruas MA: Detection of early diabetes by vitreous fluorophotometry. Diabetes 1979, 28: 16-19.

${ }^{29}$ Krogsaa B, Lund-Andersen H, Mehlsen J, Sestoft $\mathrm{L}$, Larsen $\mathrm{J}$ : The blood retinal barreir permeability in diabetic patients. Acta Ophthalmol 1981, 59: 689-94.

${ }^{30}$ Krogsaa B, Lund-Andersen H, Mehlsen J, Sestoft L: The blood-retinal barrier permeability to flu- orescein in normal subjects and in juvenile diabetics without retinopathy. Acta Ophthalmol 1986, 64: 173-9.

${ }^{31}$ Waltman S, Krupin T, Hanish S, Oestrich C, Becker B: Alteration of the blood-retinal barrier in experimental diabetes mellitus. Arch Ophthalmol 1978, 96: 878-9.

${ }^{32}$ Klein R, Wallow IIH, Ernest JT: Fluorophotometry: III. Streptozocin-treated rats and rats with pancreatectomy. Arch Ophthalmol 1980, 98: 2235-7.

${ }^{33}$ Jones CW, Cunha-Vaz JG, Rusin MM: Vitreous fluorophotometry in the alloxan and streptozocintreated rat. Arch Olphthalmol 1982, 100: 1141-5.

${ }^{34}$ Mäepea O, Karlsson C, Alm A: Blood-ocular and blood-brain barrier function in streptozocininduced diabetes in rats. Arch Ophthalmol 1984, 102, 1366-9.

${ }^{35}$ Bito LZ and DeRousseau CJ: Transport functions of the blood-retinal barrier system and the microenvironment of the retina. In: Cunha-Vaz JG ed. The blood-retinal barriers. New York and London: Plenum Press, 1980, 149-52.

${ }^{36}$ Karnieli E, Hissin PJ, Simpson IA, Salans LB, Cushman SW: A possible mechanism of insulin resistance in the rat adipose cell in streptozotocin-induced diabetes mellitus. J Clin Invest 1981, 68: 811-4.

${ }^{37}$ Wallberg-Henriksson H, Holloszy JO: Activation of glucose transport in diabetic muscle: Responses to contraction and insulin. Am J Physiol 1985, 249: C233-7.

${ }^{38}$ Gjedde $\mathrm{A}$ and Crone C: Blood-brain barrier glucose transfer: Repression in chronic hyperglycemia. Science 1981, 214: 456-7.

${ }^{39}$ McCall AL, Millington WR, Wurtman RJ: Metabolic fuel and amino acid transport into brain in experimental diabetes. Proc Natl Acad Sci USA 1982, 79: 5406-10.

${ }^{40}$ Ennis SR, Johnson JE, Pautler EL: In situ kinetics of glucose transport across the blood-retinal barrier in normal rats and rats with streptozocin-induced diabetes. Invest Ophthalmol Vis Sci 1982, 23: $447-56$

${ }^{41}$ DiMattio J, Zadunaisky JA, Altzuler N: Onset of changes in glucose transport across ocular barriers in streptozocin-induced diabetes. Invest Ophthalmol Vis Sci 1984, 25: 820-6.

${ }^{42}$ Alm A and Taarnhöj J: The effect of diabetes on transport through the blood-retinal and bloodbrain barriers in rats. Invest Ophthalmol Vis Sci 1988, 20 Suppl: 20. 